\title{
Gingival Margin
}

National Cancer Institute

\section{Source}

National Cancer Institute. Gingival Margin. NCl Thesaurus. Code C60722.

The crest of the gingiva surrounding a tooth. 